\title{
Dissociation of Processes in Belief: Source Recollection, Statement Familiarity, and the Illusion of Truth
}

\author{
Ian Maynard Begg, Ann Anas, and Suzanne Farinacci \\ McMaster University \\ Hamilton, Ontario, Canada
}

\begin{abstract}
This article reports 4 experiments concerning the effect of repetition on rated truth (the illusorytruth effect). Statements were paired with differentially credible sources (true vs. false). Old trues would be rated true on 2 bases, source recollection and statement familiarity. Old falses, however, would be rated false if sources were recollected, leaving the unintentional influence of familiarity as their only basis for being rated true. Even so, falses were rated truer than new statements unless sources were especially memorable. Estimates showed the contributions of the 2 influences to be independent; the intentional influence of recollection was reduced if control was impaired, but the unintentional influence of familiarity remained constant.
\end{abstract}

The truth of any proposition has nothing to do with its credibility and vice versa.

-Parker's law of political statements (Bloch, 1979, p. 84)

Our interest in this article is with the cognitive processes that influence ratings of probable truth. Ideally, a statement should not be accepted as true without factual evidence in support of its claims. However, people often rely on memories for that evidence. It is sensible to base truth ratings on whether expressed facts corroborate or contradict remembered facts. But memory is imperfect, and it is sensible to trust some remembered facts more than others. We propose that there are two independent bases on which remembered facts are given credence when people rate truth. One basis is recollection: A statement will be accepted as true if it corroborates remembered facts that are associated with a known, credible source, and it will be rejected as false if the facts are associated with a discredited source. The other basis is familiarity: A statement will seem true if it expresses facts that feel familiar. We propose, furthermore, that these two bases differ in the extent to which their influence is controlled rather than automatic. Recollection of source is a controlled use of memory, and its influence on rated truth is intentional. In contrast, increased familiarity is an automatic consequence of exposure, and its influence on rated truth is unintentional.

This research was funded by Operating Grant OGP0008122 from the Natural Sciences and Engineering Research Council of Canada; a certificate of approval from the McMaster Ethics Committee is on file. Part of the research was conducted as an honors thesis by Suzanne Farinacci, who was supervised by Ian Maynard Begg.

We are grateful for the advice and discussion from our McMaster colleagues, including Marcia Barnes, Lee Brooks, Vincenza Gruppuso, Larry Jacoby, Janine Jennings, Steve Lindsay, Douglas Needham, Rohan Robertson; James Taylor, Jeff Toth, and Andy Yonelinas. We also thank Colleen Kelley of Macalester College for her counsel. Special thanks are due to Jim Anas for being a male voice on the tapes.

Correspondence concerning this article should be addressed to Ian Maynard Begg, Department of Psychology, McMaster University, Hamilton, Ontario, Canada L8S 4K1.
Our thesis is that source recollection and statement familiarity are independent influences on rated truth, because recollecting and using source information requires intent, whereas the feeling of familiarity that occurs while processing messages occurs unintentionally. An opposing view is that the two influences are not independent: Judgments depend on familiarity only when other bases for judgments are not available. In the following section, we review the empirical support for the idea that the effect of repetition on rated truth is based on familiarity. Then, we examine evidence that familiarity and recollection are independent bases for judgments of fame and that source recollection is an intentional process. Finally, we return to rated truth and develop an approach by which we can dissociate the intentional influence of source recollection from the unintentional influence of statement familiarity.

\section{Illusory Truth}

The illusory-truth effect was first observed by Hasher, Goldstein, and Toppino (1977), who found that subjects rated repeated statements as more probably true than new statements. Repetition is an illogical basis for truth; Wittgenstein likened the tendency to believe repeated information to buying a second newspaper to see if the first one was right (Kenny, 1973). Although repetition does not provide evidence for truth, repetition does increase familiarity; for example, repeated stimuli are processed relatively fluently (cf. Jacoby \& Dallas, 1981), and repeated information is easily retrieved (cf. Tversky \& Kahneman, 1973, 1974). Is this increased familiarity the reason for the illusory-truth effect?

If the increased familiarity of repeated statements is the reason they seem truer than new ones, then statements should seem increasingly true as they repeat more old facts and reinstate more of the original context. To illustrate, consider the test statement "The extended right arm of the Statue of Liberty is $\mathbf{4 2}$ feet long." The illusory-truth effect is larger if the entire statement was presented earlier than if only "Statue of Liberty" was presented earlier, and the effect is larger if earlier queries presented more rather than fewer of the tested 
details ("Do you have any idea how long the extended right arm of the Statue of Liberty is?" vs. "Do you have any idea how long the Statue of Liberty has been in New York?"; Begg, Armour, \& Kerr, 1985). Test statements are also rated falser than new ones if they convey unfamiliar details that contradict studied statements (e.g., "The extended right arm of the Statue of Liberty is 46 feet long"; Bacon, 1979). These effects of familiarity are irrational; there is no logical reason for repetition to affect rated truth or for earlier information to be trusted more than later information.

If the influence of familiarity on rated truth is independent of the influence of recollection, then the two influences should be separately manipulable. Begg et al. (1985) found that meaningful processing enhanced recognition memory for statements but did not affect the size of the illusory-truth effect. These results are parallel to those of Jacoby and Dallas (1981), who found that meaningful processing helped recognition memory for words but did not affect identification at short exposure durations. Furthermore, the explicit provision of source information does not influence rated truth. Bacon (1979) used a test in which repeated statements, new statements, and contradictory statements were presented in correctly labeled blocks. Because subjects were explicitly told at study and at test that half the statements were actually true and half were false, they knew that repeated statements were no more likely to be true than new ones and that contradictions were as likely to be true (contradicting an old false statement) as false (contradicting an old true statement). Even with this explicit information available, repeated statements were rated truer than new statements, and contradictions were rated falser than new statements.

In summary, we propose that the illusory truth of repeated statements is based on familiarity. Familiarity increases automatically with repetition, and its influence on rated truth is unintentional. Subjects do not spontaneously monitor the source of a statement's familiarity or use that information when rating truth. We next consider research in which the intentional role of recollection was examined more specifically.

\section{False Fame and the Sleeper Effect}

The sleeper effect occurs if an argument from a discredited source has a greater delayed than immediate effect on attitudes (e.g., Greenwald, Pratkanis, Leippe, \& Baumgardner, 1986; Pratkanis, Greenwald, Leippe, \& Baumgardner, 1988). According to the discounting-cue hypothesis, the effect occurs because the association between memory for the message and memory for its source is lost over time (Gruder et al., 1978); the familiarity of the message is influential only because there is no associated source that would discount it if recollected. However, if the two influences are independent, source information may remain associated with the message but have no effect on judgments; subjects do not automatically identify the source of familiarity or discount its influence.

It is difficult to discriminate the independence and dependency views in most experiments. Jacoby, Kelley, Brown, and Jasechko (1989) contrasted the two views in their investigation of the false-fame effect, which occurs if repeated nonfamous names are called famous more often than new nonfamous names. They proposed that old names are called famous because they feel familiar, although their familiarity reflects prior exposure in the experiment; this familiarity gives no objective basis for fame. Jacoby et al. opposed recollection and familiarity by telling subjects that all of the old names were actually nonfamous. Hence, recollection of the source of an old name would lead to its being called nonfamous, but its familiarity would lead to its being called famous. These exclusion instructions eliminated the false-fame effect if the test was immediate but not if the test was delayed $24 \mathrm{hr}$. This sleeper effect shows that recollection of a discredited source and familiarity are affected differently by the passage of time.

Jacoby, Woloszyn, and Kelley (1989; see also Jacoby \& Kelley, 1987, 1990,1991) proposed that the influence of recollection is intentional and controlled but that the influence of familiarity is automatic and unintentional. Jacoby et al. impaired subjects' ability to control the encoding of nonfamous names by dividing the subjects' attention at study, and they impaired subjects' ability to recollect sources by dividing their attention at test. These impairments reduced the influence of recollection; old nonfamous names became more famous, and the false-fame effect became larger.

In summary, fame judgments are jointly determined by familiarity and by recollection. The influence of recollection is under intentional control, but the influence of familiarity is unintentional. When the capacity for control is impaired, familiarity is unopposed by recollection of discredited sources.

\section{Dissociation of Processes}

The recently developed process-dissociation procedure (Jacoby, 1991; Jacoby \& Kelley, 1990, 1991) gives a theoretical basis for dissociating the influences of recollection and familiarity. An inclusion condition is one in which familiarity and recollection both have the same effect. For example, if a statement was initially paired with a credible source, either source recollection $(R)$ or statement familiarity $(F)$ would lead to a rating of true; $p$ (true) $=\mathrm{R}+\mathrm{F}-\mathrm{RF}$.' In contrast, an exclusion condition is one in which familiarity and recollection have opposite effects. A statement originally paired with an incredible source would be rated false if the source was recollected and would be rated true only if the influence of familiarity was unopposed by recollection: $p$ (true) $=\mathrm{F}-\mathrm{RF}$. Solving the equations gives values for $R$ and $F$, which are valid if they respond appropriately to experimental treatments.

The procedure includes the assumptions that the processes are independent and that both processes have the same degree of influence in the inclusion and the exclusion conditions. As

\footnotetext{
${ }^{1}$ The expression $R+F-R F$ can be expressed as $F+(1-F) R$ or as $R+(1-R) F$, which are exactly equivalent. We have used the $\mathrm{R}+\mathrm{F}-\mathrm{RF}$ form because the other forms invite misinterpretations; $\mathrm{R}+(1-\mathrm{R}) \mathrm{F}$ might be taken to mean that familiarity is influential only in the absence of recollection, and $F+(1-F) R$ might be taken to mean that recollection is influential only in the absence of familiarity. Those interpretations are wrong; both forms merely express the independence of the two processes.
} 
we see it, familiarity is a global feeling that occurs when statements are processed at test. Although familiarity is expected to increase with exposure, familiarity reflects other factors as well. For example, some statements may be familiar because of preexperimental experience with the details, and some may refer to topics with which subjects are familiar. Hence, $F$ is an estimate of the concerted influence of a feeling or impression with multiple bases. At present, the procedure does not include a way to resolve global familiarity into constituents. However, if the rated truth of new statements is about the same in conditions being compared, it is reasonable to assume that the influence of preexperimental familiarity is the same in the conditions, even though the rated truth of new statements is not a clean measure of the extent to which statements are preexperimentally familiar.

Research on judged fame included conditions in which recollection of a discredited source would discount the effect of familiarity. Begg and Armour (1991) included comparable conditions in their research on illusory truth, but they also included conditions in which recollection and familiarity would support each other. Subjects studied statements with biasing comments that were explicitly affirmative ("It is widely known that ...") or negative ("Few people believe that ...") and then rated the truth of the statements without the biases. Old affirmatives were rated truest, but even old negatives were rated truer than new statements. The rated truth of affirmatives includes both influences; a statement would be true if subjects recollected the original bias or if the statement felt familiar. However, the rated truth of negatives excludes the intentional influence of recollection; recollection of the bias would lead to a rating of false, but familiarity would lead to a rating of true. The finding that negatives were rated truer than new statements is dramatic; the statements' familiarity makes them seem true even when the influence of recollection would be to rate them false.

\section{Overview of Present Experiments}

The aim of our experiments is to contrast the intentional influence of source recollection and the unintentional influence of statement familiarity on rated truth. Statements were originally paired with sources and then were tested without the sources. For example, "Sharon Spencer says that 18 newborn opossums can be placed in a teaspoon" is a statement with a female source, and "John Yates says that 300,000 pencils can be made from the average cedar tree" is a statement with a male source. Subjects in cued conditions were told that the sources were differentially credible. They were told that females were telling the truth but males were lying, or vice versa, to define true versus false sources (we use true to mean a repeated statement with an original source that was defined as true). Our interest is with the rated truth of trues, falses, and news.

The contrast between trues and falses allows investigation of the intentional influence of source recollection to a greater extent than was possible in previous research. Although the fame research used exclusion conditions, source recollection entailed only old-new discrimination, because the discredited source was prior exposure. In the present case, both trues and falses are old, so any influence of recollection requires discrimination of sources within old statements. The falses will be rated true only on the basis of familiarity, because recollection of the source would lead to a rating of false. The trues will be rated true if the source is recollected or because they are familiar. Thus, trues should be rated truer than falses, with the difference between them reflecting recollection. The falses can be truer or falser than news because the two influences have opposite effects; they will be truer than news when the unintentional influence of familiarity exceeds the intentional influence of recollection and will become falser as the influence of recollection becomes stronger, eventually becoming falser than news. Applying the process-dissociation procedure to truth ratings makes it possible to estimate $R$, the influence of source recollection, and $F$, the influence of familiarity. If the estimates are valid, $R$ will decline when intentional control is impaired, but $F$ will remain constant over conditions in which control is intact or impaired.

Each experiment also included neutral conditions, in which there was no mention of the credibility of the sources. Because subjects were told that half the old statements and half the new statements were true, recollection would discount the effect of familiarity by identifying the prior exposure of the statements as a source of their familiarity. However, source recollection is not automatic. Therefore, old statements should be rated truer than new statements even though the subjects could, if asked, indicate which statements were presented in the study list. We place less emphasis on the neutral conditions than on the cued conditions, because most of the results of the neutral conditions confirm known results.

Our thesis is that source recollection and statement familiarity are independent influences on rated truth. The most direct way to determine if measures are independent is to see if they can be manipulated separately. For example, measures of recollection should be reduced if control is impaired, but measures of familiarity should be invariant over impairment of control. It is also possible to test for stochastic independence within conditions. If measures are independent, then an item's success on one measure should be uninformative about the item's success or failure on the other measure. We included direct tests of source memory. Rated truth should be associated with source judgments; for example, statements that are rated true should be judged to have had a true source. However, when the data are conditionalized on the basis of whether the source judgments are correct or incorrect, rated truth should be dependent only on familiarity. Therefore, we predicted that rated truth would be independent of the accuracy of source judgments. We now outline the major contrasts in each of four experiments.

In Experiment 1, each statement was paired with a male or a female name. ${ }^{2}$ Half the names were known; they had been

\footnotetext{
${ }^{2}$ We did not investigate sex as a determinant of apparent truth. Our procedures favored the two sources equally often, and our results are averaged to contrast trues versus falses. Differences between male and female sources would be unimportant because the statements we used were chosen from books of trivia. Worse, differences would be uninterpretable; the experimenter was female (and it was her voice that subjects heard when studying statements). most of the subjects
} 
learned earlier in the experiment. After subjects were told to believe females and doubt males (or vice versa), they listened to the statements and names, and then they rated the probable truth of old and new statements. The pattern in rated truth was true $>$ false $>$ new, and the true-false difference was larger with known than with unknown names. Hence, the known names enhanced source recollection. However, statements paired with known names were not more familiar than statements paired with unknown names.

In Experiment 2, subjects were told either to believe or to doubt male or female names; truth ratings were true $>$ false $>$ new. On a second test, subjects rated truth and made memory judgments. Truth ratings were independent of the accuracy of source judgments even though statements that were rated true tended to be judged to have had true sources.

In Experiment 3, we added a postcued condition in which subjects were told which names to believe and which to doubt after they had heard the statements and sources. Because these subjects had no truthful or untruthful sources at study, they could not exercise control over encoding of credibility and, hence, should show a reduced influence of recollection on rated truth. Postcued subjects failed to discriminate trues from falses in rated truth (true $=$ false $>$ new), but precued subjects showed the usual pattern (true $>$ false $>$ new). Postcuing reduced $R$ but did not affect $F$. This same outcome occurred in Experiment 4, in which we used male and female voices to improve source discrimination. We also included a condition in which subjects performed mental arithmetic while listening to the statements. Dividing attention had the same effect as postcuing; it reduced $R$ but had no effect on $F$.

The results confirm that the unintentional influence of familiarity is an automatic consequence of prior exposure but that the intentional influence of recollection of sources requires intentional and strategic control. Accordingly, the two influences are independent.

\section{General Method}

The experiments shared the procedural details described in this section. Departures are described in separate Method sections.

\section{Subjects}

Subjects were introductory psychology students at McMaster University who volunteered in return for course credit. They assigned themselves to groups of 9 to 15 that were assigned at random to experimental conditions, with at least two groups assigned to each condition.

\section{Materials}

Study list. Study lists consisted of statements paired with names (e.g., "Gail Logan says that house mice can run an average of 4 miles per hour"), which were tape-recorded at rates from 10 to $13 \mathrm{~s}$ per statement.

were females, and the statements were not normed as to whether the referential contents are stereotypically associated with males or females.
Statements. Statements were chosen from the pool described by Bacon (1979); each has a true version and a false version that was created by changing a detail. We reduced the pool to 196 statements; true and false versions were rated as true by .40 to .60 of the norming sample. For each experiment, we selected the number of statements needed, randomly assigned them to conditions, and then selected the true version for half the statements and the false version for the other half. Subjects were told that half the statements were actually true and half false, and the information was repeated at test to let them know that old and new statements had the same chance of being true. All results are averaged over actual truth and falsity.

Names. We chose 64 surnames from a telephone directory (Hamilton, ON). Each name filled between one quarter of a column and a full column in the directory, and each was from 4 to 9 letters long. First names were chosen from Battig and Montague (1969), including the 32 most frequent male names and the 32 most frequent female names and omitting names that are in both categories and that are derivatives of each other. First names and surnames were paired at random; some re-pairing was needed to avoid famous names. Examples include Nancy Archer, Betty Cummings, Gail Logan, and Linda Walsh versus Sam Abbott, Mike Butler, Frank Foster, and Harry Pearson.

Truth tests. Subjects rated the probable truth of old and new statements, all without names. In Experiment 1, the test was presented by tape recorder, and the response scale was certainly true (1), probably true (2), possibly true (3), completely uncertain (4), possibly false (5), probably false (6), and certainly false (7). In Experiments $2-$ 4 , the tests were typed, and the truth scale was reversed, that is, certainly true (7). Previous research has used averaged rated truth as the dependent variable, but we used the proportion of true ratings ( 1 , 2, and 3 in Experiment 1; and 5, 6, and 7 in Experiments 2, 3, and 4); analyses of average ratings led to the same conclusions, but the proportions are more tractable to stochastic analyses and are easier to understand.

\section{Procedure}

The major manipulation of the experiments consisted of cuing subjects that sources were differentially credible. Cues defined a true source and a false source by telling subjects to believe one source and doubt the other. Cues were balanced in every experiment so that each statement and source was true or false about equally often. Subjects in precued conditions were told which sources were true and which were false before they heard the study list to allow intentional control over the encoding of truthful and untruthful sources. Experiments 3 and 4 also included postcued conditions; subjects were not told which sources were true and which were false until they had heard the study list to prevent intentional control over encoding of truthful and untruthful sources. Each experiment also included a neutral condition in which there was no mention of the credibility of the sources.

\section{Experiment 1}

Subjects in Experiment 1 first learned some male and female names. Then they heard a list in which statements were paired with these known names or with unknown names. Before they heard the list, subjects were told that one source was true and one source was false. They were told either that known names were truthful and unknown names were lying (or vice versa) or that females were truthful and males were lying (or vice versa). Subjects then rated the truth of old and new statements. 
We have proposed that rated truth is based on source recollection and statement familiarity. Recollection is an intentional use of memory to comply with explicit information about source credibility. In contrast, familiarity is an illogical basis for rating truth, because statements originally paired with a false source should feel more familiar than new statements. Furthermore, subjects were explicitly told that half the statements were true at study and at test. Hence, subjects should discount familiarity caused by prior exposure in the experiment. We next describe the specific predictions tested in Experiment 1.

First, trues should be rated truer than news because both familiarity and recollection would lead to a true rating. Second, trues should be rated truer than falses, with the difference based on recollection. Third, the true-false difference should be larger if the source names are known rather than unknown. Fourth, the false-new difference should vary inversely with the influence of recollection. The two influences have opposite effects on falses, which would be rated true on the basis of familiarity and false on the basis of recollection. Thus, the false-new difference should be greater with known than with unknown sources. We also used the process-dissociation procedure to estimate the influence of recollection and familiarity on the rated truth of the trues and falses. If the two influences are independent, then the proportion of trues rated true is $\mathbf{R}$ $+F-R F$, and the proportion of falses rated true is F - RF. We predicted that $R$ would be higher with known than with unknown names as sources but that $F$ would not. If anything, $F$ could decline with known sources, because the known sources are familiar, and subjects might attribute the feeling of familiarity to the sources rather than to the statements.

\section{Method}

\section{Subjects}

A total of 195 subjects were tested; 34 were in each of two neutral conditions; 59 were cued about the credibility of known and unknown names, and 68 were cued about male and female names.

\section{Materials}

Thirty-two female and 32 male names were paired with 64 statements that were selected from the pool, as were 20 new statements for the test. There were 16 statements for each source (Known or Unknown $\times$ Male or Female), but only 10 of each were tested later. The study list was tape-recorded at a rate of $10 \mathrm{~s}$ per statement. The test included 20 new statements and 40 old ones (10 from each source), all without names. The statements were tape-recorded in random order at a rate of $10 \mathrm{~s}$ per statement by the same person who had recorded the study list.

\section{Procedure}

Known names. Subjects initially learned 16 male and 16 female names. They heard the names (e.g., Mary Freeman and Ken Rankin) at a rate of $2 \mathrm{~s}$ per name, then had four tests of memory for the names. On each test trial, subjects heard part of each name and had $5 \mathrm{~s}$ to write the rest, after which they heard the full name. Each name was tested four times, prompted twice by the first name and twice by the surname. The procedure took about $15 \mathrm{~min}$.

Study. Subjects were told to imagine they were at a party where people would make statements; half the names would be known and half would be unknown, and half would be male and half female. Subjects in one neutral condition rated the truth of each statement as it appeared. All other subjects rated how interesting the statements were on a 7-point scale with most interesting (1); we used this task to ensure that subjects attended to the meaning of each statement. Subjects in cued conditions were told before study that one source was true and one was false; they were also told which speakers would be truthful and which would be lying. Cues were based on whether the names were known or on sex.

\section{Results and Discussion}

Our interest is with the proportion of statements subjects rated true when the statements were tested without named sources. Throughout the article, the alpha level is .05 for inferences. Simple effects were evaluated by least significant differences (LSDs) based on mean square error $\left(M S_{\mathrm{e}}\right)$ values.

\section{Cued Conditions}

Table 1 shows the results for the cued conditions, with rated truth at the left side and values of $R$ and $F$ at the right side. First, consider rated truth, for which the mean square error was less than 0.032 . The pattern in each row is true $>$ false $>$ new. The first row shows the results when subjects were cued to believe or doubt names that were unknown or known; the main effect was reliable, $F(2,116)=27.4, \mathrm{LSD}=.06$. The bottom two rows show the results when cues were based on the sex of the source. There was a reliable main effect in an analysis comparing the four kinds of old statements with the new ones, $F(4,268)=17.7, \mathrm{LSD}=.06$. In a separate analysis of the old statements, there was a reliable interaction between true versus false and known versus unknown sources, $F(1,67)$ $=9.48, \mathrm{LSD}=.05$.

Values of $\mathrm{R}$ and $\mathrm{F}$ were computed separately for each subject. For the subjects whose cues were based on male and female names, $\mathrm{R}$ was larger if the sources were known rather than unknown, $F(1,67)=9.48, M S_{\mathrm{e}}=0.043$, but $\mathrm{F}$ was slightly smaller for known than unknown sources, $F(1,67)=$ $4.38, M S_{\mathrm{e}}=0.016$.

Table 1

Rated Truth of Old True, Old False, and New Statements in Experiment I

\begin{tabular}{lccccc}
\hline & \multicolumn{5}{c}{ Rated truth } \\
\cline { 2 - 5 } \multicolumn{1}{c}{ Basis of cuing } & True & False & New & R & F \\
\hline Known vs. unknown & .66 & .59 & .45 & .07 & .63 \\
Male vs. female & & & & & \\
$\quad$ Known names & .63 & .48 & .44 & .15 & .57 \\
$\quad$ Unknown names & .63 & .58 & .44 & .04 & .62 \\
\hline
\end{tabular}

Note. True refers to a repeated statement with an original source that was defined as true. False refers to a repeated statement with an original source that was defined as false. New refers to a statement that was not originally studied. $\mathrm{R}=$ recollection; $\mathrm{F}=$ familiarity. 


\section{Neutral Condition}

Subjects in the neutral condition showed the illusory-truth effect. They rated .60 of the old statements true, compared with .44 of the new ones; the main effect was reliable, $F(1,33)=11.7, M S_{\mathrm{e}}=0.014$. Averaged over old and new statements, subjects rated .55 of the statements true. Subjects who rated truth at study rated .54 of the statements true $\left(M S_{\mathrm{e}}\right.$ $=0.033$ ). Hence, subjects adopted a criterion level of plausibility that accepted about half the statements as true. The mean ratings at study, when all statements were new, fell between the means for old and new statements rated after study. The familiarity of the old statements increased their apparent truth and the relative unfamiliarity of the new statements reduced their apparent truth. The occurrence of the illusory-truth effect in the neutral condition implies that subjects did not spontaneously identify the source of the statements' increased familiarity as being prior exposure in the experiment and discount the influence of familiarity.

\section{Summary and Conclusions}

The pattern in rated truth was true $>$ false $>$ new. The trues were rated truest because familiarity and source recollection both lead to a rating of true. These two influences have opposite effects with falses because source recollection would lead to a rating of false. Furthermore, recollection was more influential if the sources were known than if they were unknown; known sources increased the true-false difference and decreased the false-new difference. Although $\mathrm{R}$ was larger with known than unknown sources, $F$ was not, indicating that they respond differently to the manipulation of whether sources are known or unknown.

\section{Experiment 2}

Subjects in Experiment 2 studied statements paired with female and male names before rating the truth of old and new statements. As in Experiment 1, we expected that rated truth would be true $>$ false $>$ new. Subjects then completed a second test that included truth ratings and source judgments. Statements that are rated true should be attributed to the true source, whether the basis for apparent truth is recollection or familiarity. To the extent that rated truth reflects familiarity, rated truth should be independent of the accuracy of source judgments.

\section{Method}

\section{Subjects}

There were 75 subjects, 25 in the neutral condition and 50 in the cued condition.

\section{Materials}

We chose 30 new statements for the tests, 60 studied statements, and 4 untested fillers ( 2 at each end of the study list). The 64 names were paired with the 64 studied statements and tape-recorded at a 12-s rate. Subjects rated interest at study, circling a digit from 1 to 7 for each statement, with most interesting (7). The truth test had 20 new statements and 20 old statements (10 from each source). Each statement was typed beside the 7-point truth scale, with certainly true (7). The truth-and-memory test had another 20 old statements (10 from each source) and 10 new statements. Each statement was accompanied by the truth scale and by $N$ for new, $M$ for male, and $F$ for female.

\section{Procedure}

Subjects were to imagine they were at a party playing Trivial Pursuit and that 32 women and 32 men would each present a trivial statement. They rated how interesting each one was. Subjects in the neutral condition received no biasing cues. Subjects in the cued condition were told that the men would most often be telling the truth and the women would most often be lying, or vice versa. Subjects completed the truth test $(7 \mathrm{~min})$ and then the truth-andmemory test $(6 \mathrm{~min})$.

\section{Results and Discussion}

\section{Cued Condition}

Rated truth. Table 2 shows the truth ratings for the cued condition. Ratings showed the same pattern as in Experiment 1, true $>$ false $>$ new. The main effect was reliable on each test, $F(2,98)>21.7, M S_{\mathrm{c}}<0.024, \mathrm{LSD}=.06$. Table 2 also shows the $\mathrm{R}$ and $\mathrm{F}$ values. Neither $\mathrm{R}\left(M S_{\mathrm{e}}=0.039\right)$ nor $\mathrm{F}$ $\left(M S_{c}=0.021\right)$ differed over tests. Thus, the requirement to make memory judgments did not affect truth ratings.

Memory. Subjects accurately discriminated old from new statements. They recognized .94 of the trues and .93 of the falses, and falsely recognized only .10 of the news $(.05$ were attributed to each source; $M S_{\mathrm{c}}<0.020$ ). However, subjects were less accurate in judging whether recognized statements had true or false sources. Source discrimination was assessed by $\mathrm{D}=p$ ("true" $\mid$ true $)-p$ ("true" $\mid$ false $) ;$; subjects showed reliable discrimination, $\mathrm{D}=.63-.45=.18, F(1,49)=28.9$, $M S_{\mathrm{c}}=0.029$. Finally, we assessed the relationship between rated truth and the accuracy of source judgments and found that the two were independent. Rated truth was about the same for correctly judged trues as for falses that were misjudged as having true sources (.82 vs. .84) and for trues that

\footnotetext{
${ }^{3}$ Batchelder and Riefer (1990) observed that there is no theoryfree way to measure the accuracy of memory for source. They presented a multinomial model in which memory for source can be measured under defined sets of assumptions. The traditional measure of source memory is $I$ (the average proportion of correct source judgments, given recognition). Batchelder and Riefer showed that $I$ is not independent of recognition. However, when hit rates are high and false alarm rates are low, the dependency has little effect; $2 I-1$ is approximately equal to their parameter that estimates discriminability of sources. We used their model to analyze the data from each experiment, but there was rarely more than a $1 \%$ discrepancy in estimates of discriminability computed by the multinomial model and computed as the difference between hits ("true" | true) and false alarms ("true" | false), given recognition. We present the simpler, traditional estimates.
} 
Table 2

Truth of Old True, Old False, and New Statements in Experiment 2

\begin{tabular}{cccccc}
\hline \multicolumn{5}{c}{ Rated truth } & \\
Test & True & False & New & R & F \\
\hline 1 & .70 & .60 & .49 & .11 & .68 \\
2 & .71 & .65 & .49 & .07 & .71 \\
\hline
\end{tabular}

Note. True refers to a repeated statement with an original source that was defined as true. False refers to a repeated statement with an original source that was defined as false. New refers to a statement that was not originally studied. $R=$ recollection; $F=$ familiarity.

were misjudged as having false sources as for correctly judged falses (.54 vs. .52). Analysis revealed a main effect of judged source, $F(1,49)=34.7, M S_{\mathrm{e}}=0.13$, but no effect of actual source, $F(1,49)=0.012, M S_{\mathrm{e}}=0.052$.

\section{Neutral Condition}

Subjects in the neutral condition rated more old than new statements true on the first test $(.73>.46)$ and on the second test $(.80>.46)$. Both main effects were reliable, $F(1,24)>$ $20.8, M S_{\mathrm{e}}<0.045$. On the second test, subjects correctly recognized .96 of the old statements and falsely recognized .10 of the new ones $\left(M S_{\mathrm{e}}=0.012\right)$. Thus, the illusory-truth effect occurs even when subjects know that the statements were presented recently.

\section{Summary and Conclusions}

The results support and extend the conclusions from Experiment 1. Rated truth was true $>$ false $>$ new. On the memory test, subjects discriminated old and new statements very accurately. Memory for sources was modest, even though subjects were explicitly directed to attend to the sources at study. Rated truth was independent of whether source judgments were correct or incorrect, even though there was a strong association between rated truth and source judgments.

\section{Experiment 3}

Statements were paired with male and female names at study but not at test. We added a postcued condition in which the credibility of the sources was not mentioned until after the statements and sources had been heard. Because subjects in postcued conditions did not have true versus false sources while studying, they could not control encoding to take account of source credibility. Impairing their control should reduce their ability to discriminate between true and false sources in truth ratings and also on direct test of memory. However, because the influence of familiarity on rated truth is unintentional, impairment of control should have no effect on familiarity. We predicted that precued and postcued conditions would differ in $\mathrm{R}$ but not in $\mathrm{F}$.

After subjects rated truth, they completed a memory test on which some of the statements were repeated from the truth test. We extended the process-dissociation procedure as fol- lows. We used the ratings from the truth test to identify consistent statements (trues rated true and falses rated false) and inconsistent statement (trues rated false and falses rated true), and then we examined source judgments from the memory test. In both cases, source judgments would be correct if they were based on recollection. However, judgments based on apparent truth or falsity would give different answers for the two sorts of statement. Consistent statements that seem true actually had a true source, and those that seem false had a false source. With inconsistent statements, the ones that seem true actually had a false source, and the ones that seem false had a true source; judgments that accord with apparent truth would be wrong. For consistent statements, the probability of a correct source judgment is $R+F-R F$; for inconsistent statements, the probability is $F-R F$ that the statement will be attributed to the accordant but incorrect source. Solving these equations for $\mathrm{R}$ and $\mathrm{F}$ allows comparison of the influences on a direct test of memory with those on a test of truth, which is an indirect test of memory.

\section{Method}

\section{Subjects}

There were 74 subjects, 25 in the neutral condition, 25 in the precued condition, and 24 in the postcued condition.

\section{Materials}

We chose 60 new statements for the tests, 60 old statements, and 4 fillers ( 2 at each end of the list). Each statement was paired with a name and tape-recorded at a rate of $13 \mathrm{~s}$ per pair, of which $4 \mathrm{~s}$ was blank. The truth test had 40 new statements and 40 old statements ( 20 from each source). At the top of each page was the legend for the 7 -point scale, with the digits 1 to 7 typed beside each statement. The memory test had 20 new statements, 20 old statements that had not been rated for truth, and 20 that had been rated for truth; half of the old statements were from each source. Beside each statement were $M$ for male, $F$ for female, and $N$ for new.

\section{Procedure}

Subjects in the neutral condition were not told to believe or to doubt either source. Precued subjects were told before study to believe one sex and doubt the other; the instructions were repeated at test. Postcued subjects received the same test instructions after hearing the statements and sources. Subjects were told to listen carefully to each statement. Immediately after each statement, the experimenter held up a card $(8.5 \times 11 \mathrm{in}$.) with a number from 11 to 89 on it; subjects recorded this number on a sheet that was numbered to correspond to the presented statements. Subjects then completed the two tests, which required about $13 \mathrm{~min}$ and $6 \mathrm{~min}$, respectively.

\section{Results and Discussion}

\section{Cued Conditions}

Rated truth. Rated truth for the cued conditions is shown at the left side of Table 3. Rated truth in the precued condition showed the same pattern as in Experiments 1 and 2: true > 
Table 3

Rated Truth of Old True, Old False, and New Statements in Experiment 3

\begin{tabular}{|c|c|c|c|c|c|c|c|c|}
\hline \multirow[b]{2}{*}{ Condition } & \multicolumn{3}{|c|}{ Rated truth } & \multicolumn{2}{|c|}{$\begin{array}{l}\text { Truth } \\
\text { data }\end{array}$} & \multicolumn{3}{|c|}{ Memory data } \\
\hline & True & False & $\overline{N e w}$ & $\mathrm{R}$ & $F$ & $\mathrm{D}$ & $\mathbf{R}$ & $\mathrm{F}$ \\
\hline $\begin{array}{l}\text { Precued } \\
\text { Postcued }\end{array}$ & $\begin{array}{l}.77 \\
.66\end{array}$ & $\begin{array}{l}.58 \\
.66\end{array}$ & $\begin{array}{l}.43 \\
.50\end{array}$ & $\begin{array}{l}.19 \\
.00\end{array}$ & $\begin{array}{l}.71 \\
.67\end{array}$ & $\begin{array}{l}.23 \\
.10\end{array}$ & $\begin{array}{l}.20 \\
.10\end{array}$ & $\begin{array}{l}.75 \\
.72\end{array}$ \\
\hline
\end{tabular}

Note. True refers to a repeated statement with an original source that was defined as true. False refers to a repeated statement with an original source that was defined as false. New refers to a statement that was not originally studied. $\mathrm{R}=$ recollection; $F=$ familiarity; $D$ $=$ accuracy of source discrimination.

false $>$ new. However, the pattern in the postcued condition was true $=$ false $>$ new. Analysis revealed a reliable interaction between the types of statements and cuing conditions, $F(2,94)=6.67, M S_{\mathrm{c}}=0.021, \mathrm{LSD}=.09$. Table 3 also shows $\mathrm{R}$ and $\mathrm{F}$ values computed from the truth data. As predicted, $\mathrm{R}$ was larger in the precued than the postcued condition, $F(1$, 49) $=9.53, M S_{\mathrm{c}}=0.046$, but $\mathrm{F}$ did not differ, $F(1,49)=$ $1.36, M S_{\mathrm{c}}=0.019$.

Memory for statements. Statements that were previously tested for truth were recognized better than statements that were tested only for memory, $.92>.85, F(1,46)=20.7, M S_{\mathrm{e}}$ $=0.013$. Recognition was equally good for precued subjects and postcued subjects (.89 vs. .87$)$ and for statements with true and false sources ( .88 vs. .88 ). The false recognition rate was .10 ; of these false recognitions, .06 were judged to have a true source, and .05 were judged to have a false source $\left(M S_{\mathrm{e}}\right.$ $=0.0049$ ).

Memory for sources. The discrimination between sources of recognized statements was assessed by $\mathrm{D}=p$ ("true" | true) - $p$ ("true" | false); these values are shown in Table 3. Discrimination was better for the precued condition $(D=.67-$ $.44=.23)$ than the postcued condition $(D=.62-.52=.10)$; the interaction was nearly reliable, $F(1,46)=3.19, M S_{\mathrm{e}}=$ $0.069, p<.08, \mathrm{LSD}=.15$. As in Experiment 2, statements that were judged to have had true sources were more likely to have been rated true than statements judged to have had false sources, $.82>.45, F(1,42)=55.6, M S_{\mathrm{c}}=0.111$, and there was no effect of whether statements actually had true or false sources (.65 vs. .62). However, there was an interaction between actual source and conditions, $F(1,42)=9.03, M S_{\mathrm{c}}=$ $0.048, \mathrm{LSD}=.13$; rated truth was higher for true than false sources in the precued condition $(.71>.58)$ but not in the postcued condition (.59 vs. .66).

We now contrast consistent statements (which had truth ratings in accord with the source) with inconsistent statements (which had truth ratings opposite to the source); analyses are based on group totals. On the memory test, subjects would attribute consistent statements to the accordant, correct source on the basis of source recollection or familiarity; respective means were .80 and .75 for the precued and postcued conditions. Inconsistent statements, however, would be attributed to the accordant, incorrect source only if familiarity was unopposed by recollection; respective means were .60 and .65 . Values of $R$ and $F$ are shown at the right side of
Table 3. The $R$ and $F$ values from the different sets of data are similar enough to be seen as telling the same story, and the $R$ values are similar to the $D$ values from the preceding analysis.

\section{Neutral Condition}

Subjects in the neutral condition rated more old than new statements true $(.72>.55)$; the main effect was reliable, $F(1,24)=17.9, M S_{\mathrm{e}}=0.019$. On the memory test, subjects recognized more statements that had been rated for truth than statements that were tested only for memory (.90 vs. .81); $F(1,24)=15.7, M S_{\mathrm{e}}=0.013$. Subjects falsely recognized .05 of the new statements. To analyze memory for the sources of the recognized statements, we tagged sources as $A$ versus $B$ (males were A for about half the subjects); $\mathrm{D}=p($ ("A" $\mid \mathrm{A})-$ $p$ (“A" | B). Analysis revealed a slight but reliable main effect; $\mathrm{D}=.57-.48=.09, F(1,24)=4.74, M S_{\mathrm{e}}=0.038$. Source recollection had a negative effect on rated truth; statements with correctly judged sources were rated true on the prior test less often than statements with incorrectly judged sources (.67 $<.76), F(1,23)=4.72, M S_{\mathrm{c}}=0.020$.

\section{Summary and Conclusions}

The results of Experiment 3 extend those from Experiments 1 and 2. Truth ratings did not differ for statements paired with true versus false sources in postcued conditions, and these subjects did not exceed chance accuracy on a direct test of source memory. Precued and postcued conditions differed in $R$ but not in $F$, whether $R$ and $F$ were computed from truth ratings or from memory judgments. Source judgments about consistent and inconsistent statements showed that familiarity was so influential that statements were attributed to the accordant but incorrect source more often than to the correct source, just as the rated truth of falses exceeded the rated truth of news. Despite the association between rated truth and source judgments, rated truth remained nearly independent of the accuracy of source judgments. An interesting finding occurred in the neutral condition, in which prior ratings of truth were higher for statements with incorrectly rather than correctly judged sources on a later test of memory; recollection of the sources was thus negatively associated with the size of the illusory-truth effect.

\section{Experiment 4}

One aim in Experiment 4 was to increase the influence of recollection by improving memory for sources; statements were recorded in a male voice or a female voice rather than being presented by male or female names. As source recollection becomes more influential, the rated truth of trues and falses should diverge, with falses becoming falser than news if recollection becomes influential enough. We included a postcued condition to impair intentional control over encoding of the credibility of the sources. We also included a condition in which subjects' attention was divided at study by doing mental arithmetic while listening to the statements. 
Dividing attention should impair subjects' ability to encode the credibility of the sources. If so, $\mathrm{R}$ will be higher in the precued condition than in the postcued condition or the divided-attention condition; $F$ will remain constant over conditions if the unintentional influence of familiarity is insensitive to impairments in control.

\section{Method}

\section{Subjects and Materials}

There were 144 subjects, with from 22 to 26 in each of 6 conditions. The materials were the same as in Experiment 3 except that the statements were recorded without names. Instead, a man recorded the statements that were paired with male names, and a woman recorded those that were paired with female names. The same tests were used as in Experiment 3 (the two experiments were set up and conducted together).

\section{Procedure}

The neutral, precued, and postcued conditions were the same as in Experiment 3 except that the sources were defined by voices rather than by names. Immediately after each statement, the experimenter held up a card containing a 2-digit numeral from 11 to 89 ; subjects recorded this number on an answer sheet. Subjects in the dividedattention condition listened to the same tape, but the 2-digit number was held up before rather than after the statement, and they recorded the difference between the number on the card and 100 after the statement had been presented. For example, they might see 27 , then hear a statement, then record 73 . The 2-digit numbers were different for all 64 trials, and very easy numbers (e.g., 25, 50, and 80) were not used. There were two divided-attention conditions (precued and postcued), but they are averaged in all later analyses because they were never reliably different from each other; if subjects are prevented from attending to source credibility, it does not matter if they are told to do so or not. After study, subjects completed the truth test ( 13 $\mathrm{min})$ and then the memory test $(6 \mathrm{~min})$.

\section{Results and Discussion}

\section{Cued Conditions}

Rated truth. Rated truth from the cued conditions is shown at the left side of Table 4. Analysis revealed a three-

Table 4

Rated Truth of Old True, Old False, and New Statements in Experiment 4

\begin{tabular}{|c|c|c|c|c|c|c|c|c|}
\hline \multirow[b]{2}{*}{ Condition } & \multicolumn{3}{|c|}{ Rated truth } & \multicolumn{2}{|c|}{$\begin{array}{l}\text { Truth } \\
\text { data }\end{array}$} & \multicolumn{3}{|c|}{$\begin{array}{l}\text { Memory } \\
\text { data }\end{array}$} \\
\hline & True & False & New & $\mathbf{R}$ & $F$ & $\mathrm{D}$ & $\mathbf{R}$ & $\mathbf{F}$ \\
\hline Precued & .78 & .40 & .46 & .38 & .64 & .43 & .37 & .78 \\
\hline Postcued & .72 & .59 & .51 & .13 & .68 & .25 & .22 & .73 \\
\hline Divided attention & .72 & .50 & .47 & .21 & .64 & .24 & .21 & .76 \\
\hline
\end{tabular}

Note. True refers to a repeated statement with an original source that was defined as true. False refers to a repeated statement with an original source that was defined as false. New refers to a statement that was not originally studied. $R=$ recollection; $F=$ familiarity; $D$ $=$ accuracy of discrimination. way interaction among cuing (precued vs. postcued), attention (full vs. divided), and source (true vs. false vs. new), $F(2,186)$ $=2.99, p=.05, M S_{\mathrm{c}}=0.023, \mathrm{LSD}=.09$. The row called divided attention shows the average of the two divided-attention conditions, which did not differ reliably from each other. The pattern in the precued condition was true $>$ new $\geq$ false; falses were not reliably falser than news. The falses in the postcued and divided-attention conditions were truer than in the precued condition, but they were not reliably truer than news; the pattern was true $>$ false $\geq$ new.

Table 4 also shows values of $R$ and $F$ computed from the truth ratings. Analysis of $\mathrm{R}$ revealed an interaction between attention and when cuing occurred, $F(1,93)=5.07, M S_{\mathrm{e}}=$ 0.053 , LSD $=.13$; $\mathrm{R}$ was higher in the precued condition than in the postcued condition or the divided-attention condition. In contrast, the $\mathrm{F}$ values for the three conditions did not differ reliably $\left(M S_{\mathrm{e}}=0.031, \mathrm{LSD}=.10\right)$.

Memory for statements. The major result in recognition memory was that dividing attention reduced memory. More of the previously untested statements were recognized in the precued and postcued conditions (.87 in both conditions) than in the divided-attention condition (.74); the difference was reduced for statements that were previously rated for truth $(.95$ and .93 vs. .90$)$; for the interaction, $F(2,93)=5.11$, $M S_{\mathrm{c}}=0.062$. Recognition was equally good for trues and falses ( .87 and .85$)$. False recognition rates were lower in the precued and postcued conditions $(.07$ and .08$)$ than in the divided-attention condition $(.18) ; F(2,93)=6.11, M S_{\mathrm{c}}=$ 0.021 . Falsely recognized statements were equally often attributed to true and false sources (.06 vs. $.05, M S_{\mathrm{e}}=0.0047$ ). Hence, the only factor that influenced old-new recognition was attention.

Memory for sources. Source discrimination was better in the precued condition $(\mathrm{D}=.73-.30=.43)$ than in the postcued condition $(\mathrm{D}=.65-.40=.25)$ or in the dividedattention condition $(\mathrm{D}=.65-.41=.24)$; for the interaction, $F(2,93)=4.36, M S_{\mathrm{e}}=0.079, \mathrm{LSD}=.14$. Table 4 shows that the $D$ values are higher than the $R$ values from truth ratings, but the $D$ values show the same pattern. The next analysis concerns rated truth for statements with actual sources that were true versus false and were judged to have had true versus false sources. There was a large effect of whether statements were judged to have true versus false sources $(.81>.44)$; $F(1,86)=108, M S_{\mathrm{e}}=0.093$, and a reliable effect of actual true versus false sources $(.68>.57), F(1,86)=11.3, M S_{\mathrm{c}}=$ 0.084 .

As in Experiment 3, we compared consistent and inconsistent statements. For the consistent statements, people correctly identified the source, with respective means of $.86, .79$, and .81 for the precued, postcued, and divided-attention conditions. For the inconsistent statements, people attributed the statements to the accordant but incorrect source, with respective means of $.49, .57$, and .60 . The $R$ and $F$ values from these means are shown at the right side of Table 4. Values of $R$ were reasonably close to the values computed from truth ratings, indicating that the intentional influence of recollection was about the same for rated truth as for a direct test of memory for sources. Values of $F$ were higher on the memory test because the statements received an extra pres- 
entation on the truth test, but $F$ was nearly constant over conditions, implying that the influence of familiarity is unaffected when control is impaired.

\section{Neutral Conditions}

Subjects in the neutral conditions rated more old than new statements true, and the difference was larger if subjects' attention was divided at study $(.70>.51)$ than if attention was undivided $(.64>.57)$; for the interaction, $F(1,45)=7.56$, $M S_{\mathrm{e}}=0.013, \mathrm{LSD}=.07$. In recognition memory, subjects whose attention was divided recognized fewer statements than subjects whose attention was undivided $(.79<.88)$, and they falsely recognized more of the new statements $(.13>.01)$; both main effects were reliable, $F(1,45)=10.4$ and $12.2, M S_{\mathrm{e}}$ $=0.042$ and 0.013 . Subjects showed better discrimination of sources if their attention was undivided $(D=.69-.31=.38)$ than if their attention was divided $(D=.62-.54=.08)$; for the interaction, $F(1,45)=11.3, M S_{\mathrm{e}}=0.093, \mathrm{LSD}=.17$.

Thus, dividing attention increased the size of the illusorytruth effect but reduced memory for statements and sources. Because dividing attention made memory worse but increased the illusory-truth effect, one would not want to explain the increased illusion of truth on the basis of recollection.

\section{Summary and Conclusions}

In Experiment 4, we used male and female voices rather than names, and the sources were more discriminable than in previous experiments. Accordingly, the true-false difference was large in the precued condition, and falses became slightly falser than news. Impairing control by postcuing or by dividing attention reduced the influence of recollection on rated truth, and the falses became truer than in the precued condition. Despite these changes in truth ratings, values of $F$ were nearly constant over the conditions. All measures of the accuracy of memory were reduced by dividing attention. Like dividing attention, postcuing reduced source discrimination on the direct test and on truth ratings, but postcuing had no effect on memory for statements. Hence, the similar effects on rated truth for the postcued and divided-attention conditions cannot be explained on the basis of recollection of statements. Finally, the values of $R$ and $F$ from the memory test told the same story as those from the truth ratings: Impaired control reduced $R$, but $F$ was approximately constant.

\section{General Discussion}

We conclude that rated truth is influenced by source recollection and statement familiarity and that the two influences are independent of each other. Recollection is a controlled and intentional use of cognitive information, but familiarity's influence is unintentional. We now summarize the results that support this conclusion, then review related ideas.

The illusory-truth effect occurred in the neutral conditions of each experiment, and rated truth was dissociated from the accuracy of memory judgments. For example, dividing atten- tion impaired memory for the statements and sources but increased the illusory-truth effect. Recognition memory was very accurate, indicating that subjects can identify the source of the familiarity of old statements as being their prior exposure in the experiment. However, they do not spontaneously use that information to discount the illusion of truth engendered by familiarity.

The most important results occurred when the influence of recollection of true or false sources supported or opposed the influence of familiarity on truth ratings. In Experiments 1, 2, and 3 , rated truth was true $>$ false $>$ new when subjects were precued about source credibility. Experiment 3 included a postcued condition, in which the pattern, true $=$ false $>$ new, indicates that subjects did not discriminate the sources. The conclusions were strengthened by using a process-dissociation procedure to obtain separate estimates of the influence of recollection and familiarity. If source recollection is an intentional use of memory, $R$ should decline as intentional control is impaired. If the influence of statement familiarity is unintentional, F should be unaffected by impairment of control. We found that $R$ was lower in the postcued condition than in the precued condition, but $F$ did not change. As well, $R$ was increased by the use of known rather than unknown sources in Experiment 1, but without an increase in F. The conclusions were strengthened further in Experiment 4. Source recollection was more influential with voices than with names as the basis for defining true versus false sources, and the illusory-truth effect with falses was eliminated. When control was impaired, falses were more likely to be rated true. The value of $R$ was lower in the postcued condition and the divided-attention condition than in the precued condition. However, $F$ was nearly constant over the conditions.

The most interesting result concerning the relationship between rated truth and memory judgments occurred when we compared statements having truth ratings that were consistent with the credibility cues with statements having truth ratings that were inconsistent with the cues. On a test of memory for source, both types of statements would be correctly classified if sources were recollected. The consistent statements would also be correct if they were classified on the basis of their apparent truth, but the inconsistent ones would not. Estimates of $\mathbf{R}$ from the direct test of memory were higher in precued conditions than in the postcued or dividedattention conditions, and the estimates were similar to the estimates from rated truth and from direct measures of source discrimination. Nonetheless, F remained constant over impairment of control.

\section{Memory-Based Misattributions}

We have stressed unintentional versus intentional influences of memory rather than implicit versus explicit tests of memory (Schacter, 1987; Tulving \& Schacter, 1990). Rated truth is an implicit test of memory that does not require memory for the occasion on which the statements first appeared. We have no quarrel with naming tests by whether they refer to prior events in the experiment. However, we do not want to associate each test with a different memory system. We prefer to think there is only one memory but that 
it can have different influences depending on how and why it is used.

A typical dictionary defines memory as the capacity to bring previous experiences back to mind. Memory researchers, however, consider conscious recollection to be only one side of memory. There has been much recent interest in cases in which a person's performance is influenced by specific prior events even though the person fails to remember those events on explicit tests (Jacoby, 1991; Richardson-Klavehn \& Bjork, 1988; Roediger, 1990; Roediger \& Blaxton, 1987; Schacter, 1987; Tulving \& Schacter, 1990). For example, amnesic patients usually fail to recall or recognize words studied earlier in an experiment, but they commonly produce those words as solutions on fragment-completion tests and as intrusions on other tests (Warrington \& Weiskrantz, 1974; Weiskrantz \& Warrington, 1975). Jacoby and Kelley (1987) described an amnesic patient who laughed at a joke but did not laugh when the joke was repeated; he said the joke was "dumb." Tulving (1983, p. 114) described a patient who was told that Marlboros are the world's most popular brand of cigarettes and who later was able to provide that information when asked. However, he did not recollect the source of the information; he said, "I must have read it somewhere." From our point of view, amnesic patients show extreme deficits in source recollection, but familiarity is relatively intact.

Because source recollection is not automatic, people with normal memories make errors by failing to identify the source of current experiences. For example, unconscious plagiarism occurs when an idea is attributed to one's creative process rather than to a particular past, external source; ideas do not automatically indicate whether they are being remembered or created (Jacoby, Kelley, \& Dywan, 1989). People also misattribute a current experience to the past when a new item that is related to an old one is falsely recognized as old (Underwood, 1965). The confusion between the present and the past has a parallel with confusions between internal and external sources (e.g., Johnson, 1988).

Global impressions like the feeling of familiarity are usually caused by many factors. Some have their source in the present, some in the past; some sources are internal, some external. We can separate these factors in experiments, but impressions do not automatically identify their sources, and people fail to discount the influence of irrelevant factors. Tversky and Kahneman's (1973) availability heuristic leads to errors if examples are available for the wrong reasons; for example, if a list includes names of familiar females and unknown males, subjects judge there were more females even if there were more males. Chapman (1967; see also Chapman \& Chapman, 1969; Golding \& Rorer, 1972; Yates, 1990) reported similar results for illusory correlation; clinicians overestimate the frequency of co-occurrence of symptoms that seem to go well together. Even though there are many avenues for error, estimates of frequency tend to be accurate, so much so that some theorists propose that people encode frequency automatically by changes in a dedicated frequency attribute (Hasher \& Zacks, 1979, 1984). In our view, people infer frequency from the experience of retrieval initiated by the current stimulus (Begg, Maxwell, Mitterer, \& Harris, 1986). Estimates are accurate because frequent occurrence is a major reason for experiences at retrieval. Estimates become inaccurate, however, when factors that are independent of frequency cause changes in experiences.

Subjective impressions are bases for many attributions people make about stimuli. For example, repeated words are processed more fluently than new words (Jacoby \& Dallas, 1981 ), but subjects may attribute that fluency to environmental conditions; they judge that the words are presented clearly and underestimate the level of background noise (Jacoby, Allan, Collins, \& Larwill, 1988). When Whittlesea, Jacoby, and Girard (1990) manipulated repetition and item clarity, they found that judgments of repetition were influenced by clarity and that judgments of clarity were influenced by repetition. They proposed that these illusions of memory and illusions of perception occur because subjects attribute fluent processing to past experiences or current circumstances, depending on the task. Similarly, Begg, Duft, Lalonde, Melnick, and Sanvito (1989) proposed that easily processed items give an illusion of memorability; memory predictions are accurate if the factors that cause easy processing are relevant for the memory test but are inaccurate when easy processing is because of irrelevant factors that people fail to discount.

\section{Truth Versus Belief}

We have proposed that rated truth is one member of a family of measures that are influenced by feelings or impressions that occur on a test. These impressions are often the only basis for attributing qualities to stimuli, but they are imperfectly correlated with external stimuli, and it would be smart to keep their imperfections in mind. In our experiments, any difference between old and new statements has its source in the recent past under conditions that invalidate newly learned facts as evidence for truth. The variables that make statements ring true have their source in the recent past, but they are experienced as effects of the stimulus, and the apparent truth is illusory.

It is a large step from ratings of truth to belief. Does the rated truth of trivial statements reveal anything general about belief in the world outside the laboratory? It is easy to show that belief is influenced by impressions that are created by factors that are irrelevant for truth. John Dean's confident testimony at the Watergate hearings made him a credible witness, although later comparisons between his testimony and the taped record of the events revealed many instances in which he was incorrect (Neisser, 1981). From our point of view, witness demeanor may be correlated with whether witnesses believe what they are saying, but it is absurd to assume that confident witnesses are expressing true statements, whereas witnesses who are less assured are telling untruths. For example, hypnotized subjects show increased confidence in their memories but without increases in accuracy; perhaps this is the reason for the widespread misconception that hypnosis aids memory (cf. Begg, Martin, \& Needham, in press).

Our results indicate that one basis for belief is memory; people believe statements that confirm remembered information and doubt statements that contradict it. Gilbert (1991) presented a general analysis of belief, in which he contrasted 
two models of belief, called the Cartesian model and the Spinozan model. The Cartesian model paints a picture of a rational subject. New information is registered relatively passively and is held in an unanalyzed form until detailed analysis can sort out fact from fiction. The Cartesian model gives no basis for repetition to influence apparent truth. In contrast, the Spinozan model proposes that newly registered information is tacitly accepted as true pending more detailed analysis, which can lead to the rejection of the information as false. Our results are more consistent with the Spinozan model than with the Cartesian model. We stress again, however, that there is no logical reason to place more stock in information that was encountered earlier rather than later.

\section{Final Words}

In this article, our interest has been the attribution of truth to statements that feel familiar. A direction for future research is to look at cases in which apparent truth is itself a basis for attributions. For example, people tend to accept that a conclusion is based on sound reasoning if they believe the conclusion (Wilkins, 1928), although the truth of a conclusion is irrelevant to the validity of an argument. Illusory validity is also seen when subjects accept logical arguments with conclusions that have the same atmosphere as the premises (Begg \& Denny, 1969; Sells, 1936; Woodworth \& Sells, 1935). The words used in logical tasks, like some, unintentionally and despite instructions to the contrary, are interpreted in the way they are in informal communication; these intuitive interpretations are irrelevant for validity and often lead to "illogical" decisions (Begg, 1987; Begg \& Harris, 1982). Using the process-dissociation procedure, one can contrast inclusion (intuitive conclusions that are logically valid) with exclusion (intuitive conclusions that are illogical) to separate the influence of the deliberate process of logical reasoning from the unintentional influence of intuition. We expect that logic and intuition, like recollection and familiarity, will turn out to be independent.

\section{References}

Bacon, F. T. (1979). Credibility of repeated statements: Memory for trivia. Journal of Experimental Psychology: Human Learning and Memory, 5, 241-252.

Batchelder, W. H., \& Riefer, W. M. (1990). Multinomial processing models of source monitoring. Psychological Review, 97, 548-564.

Battig, W. F., \& Montague, W. E. (1969). Category norms for verbal items in 56 categories: A replication and extension of the Connecticut category norms. Journal of Experimental Psychology Monographs, $80(3$, Pt. 2$)$.

Begg, I. (1987). Some. Canadian Journal of Psychology, 41, 62-73.

Begg, I., \& Armour, V. (1991). Repetition and the ring of truth: Biasing comments. Canadian Journal of Behavioral Science, 23. 195-213.

Begg, I., Armour, V., \& Kerr, T. (1985). On believing what we remember. Canadian Journal of Behavioral Science, 17, 199-214.

Begg, I., \& Denny, J. P. (1969). Empirical reconciliation of atmosphere and conversion interpretations of syllogistic reasoning errors. Journal of Experimental Psychology, 81, 351-354.

Begg, I., Duft, S., Lalonde, P., Melnick, R., \& Sanvito, J. (1989).
Memory predictions are based on ease of processing. Journal of Memory and Language, 28, 610-632.

Begg, I., \& Harris, G. (1982). On the interpretation of syllogisms. Journal of Verbal Learning and Verbal Behavior, 21, 595-620.

Begg, I. M., Martin, L. A., \& Needham, D. R. (in press). Memory monitoring: How useful is self-knowledge about memory? European Journal of Cognitive Psychology.

Begg, I., Maxwell, D., Mitterer, J. O., \& Harris, G. (1986). Estimates of frequency: Attribute or attribution? Journal of Experimental Psychology: Learning, Memory, and Cognition, 12, 496-508.

Bloch, A. (1979). Murphy's Law and other reasons why things go wrong. Los Angeles, CA: Price-Stern-Sloan.

Chapman, L. J. (1967). Illusory correlation in the observational report. Journal of Verbal Learning and Verbal Behavior, 6, 151155.

Chapman, L. J., \& Chapman, J. P. (1969). Illusory correlation as an obstacle to the use of valid psychodiagnostic signs. Journal of Abnormal Psychology, 74, 271-280.

Gilbert, D. T. (1991). How mental systems believe. American Psychologist, 46, 107-119.

Golding, S. L., \& Rorer, L. G. (1972). Illusory correlation and subjective judgment. Journal of Abnormal Psychology, 80, 249260.

Greenwald, A. G., Pratkanis, A. R., Leippe, M. R., \& Baumgardner, M. H. (1986). Under what conditions does theory obstruct research progress? Psychological Review, 93, 216-229.

Gruder, C. L., Cook, T. D., Hennigan, K. M., Flay, B. R., Alessis, C., \& Halamaj, J. (1978). Empirical tests of the absolute sleeper effect predicted from the discounting cue hypothesis. Journal of Personality and Social Psychology, 36, 1061-1074.

Hasher, L., Goldstein, D., \& Toppino, T. (1977). Frequency and the conference of referential validity. Journal of Verbal Learning and Verbal Behavior, 16, 107-112.

Hasher, L., \& Zacks, R. T. (1979). Automatic and effortful processes in memory. Journal of Experimental Psychology: General, 108 , 356-388.

Hasher, L., \& Zacks, R. T. (1984). Automatic processing of fundamental information: The case of frequency of occurrence. American Psychologist, 39, 1372-1388.

Jacoby, L. L. (1991). A process dissociation framework: Separating automatic from intentional influences of memory. Journal of Memory and Language, 30, 513-541.

Jacoby, L. L., Allan, L. G., Collins, J. C., \& Larwill, L. K. (1988). Memory influences subjective experience: Noise judgments. Journal of Experimental Psychology: Learning, Memory, and Cognition, 14, 240-247.

Jacoby, L. L., \& Dallas, M. (1981). On the relationship between autobiographical memory and perceptual learning. Journal of Experimental Psychology: General, 110, 306-340.

Jacoby, L. L., \& Kelley, C. M. (1987). Unconscious influences of memory for a prior event. Personality and Social Psychology Bulletin, 13, 314-336.

Jacoby, L. L., \& Kelley, C. M. (1990). An episodic view of motivation: Unconscious influences of memory. In E. T. Higgins \& R. M. Sorrentino (Eds.), Handbook of motivation and cognition: Foundations of social behavior (Vol. 2, pp. 451-481). New York: Guilford Press.

Jacoby, L. L., \& Kelley, C. M. (1991). Unconscious influences of memory: Dissociations and automaticity. In D. Milner \& M. Rugg (Eds.), Neuropsychology of consciousness (pp. 201-233). San Diego, CA: Academic Press.

Jacoby, L. L., Kelley, C. M., Brown, J., \& Jasechko, J. (1989). Becoming famous overnight: Limits on the ability to avoid unconscious influences of the past. Journal of Personality and Social Psychology, 56, 326-338. 
Jacoby, L. L., Kelley, C. M., \& Dywan, J. (1989). Memory attributions. In H. L. Roediger \& F. I. M. Craik (Eds.), Varieties of memory and consciousness: Essays in honour of Endel Tulving (pp. 391-422). Hillsdale, NJ: Erlbaum.

Jacoby, L. L., Woloshyn, V., \& Kelley, C. M. (1989). Becoming famous without being recognized: Unconscious influences of memory provided by dividing attention. Journal of Experimental $P_{s y}$ chology: General, 118, 115-125.

Johnson, M. K. (1988). Discriminating the origin of information. In T. F. Oltmanns \& B. A. Maher (Eds.), Delusional beliefs: Interdisciplinary perspectives (pp. 34-65). New York: Wiley.

Kenny, A. (1973). Wittgenstein. Harmonsworth, Middlesex, England Penguin Books.

Neisser, U. (1981). John Dean's memory: A case study. Cognition, 9 $1-22$.

Pratkanis, A. R., Greenwald, A. G., Leippe, M. R., \& Baumgardner, M. H. (1988). In search of reliable persuasion effect: III. The sleeper effect is dead. Long live the sleeper effect. Journal of Personality and Social Psychology, 54, 203-218.

Richardson-Klavehn, A., \& Bjork, R. A. (1988). Measures of memory. Annual Review of Psychology, 39, 475-543.

Roediger, H. L. (1990). Implicit memory: Retention without remembering. American Psychologist, 45, 1043-1056.

Roediger, H. L., \& Blaxton, T. A. (1987). Retrieval modes produce dissociations in memory for surface information. In D. S. Gorfein \& R. R. Hoffman (Eds.), Memory and cognitive processes: The Ebbinghaus centennial conference (pp. 349-379). Hillsdale, NJ: Erlbaum.

Schacter, D. L. (1987). Implicit memory: History and current status. Journal of Experimental Psychology: Learning, Memory, and Cognition, $13,501-518$.

Sells, S. B. (1936). The atmosphere effect: An experimental study of reasoning. Archives of Psychology, 29, 3-72.

Tulving, E. (1983). Elements of episodic memory. New York: Oxford University Press.
Tulving, E., \& Schacter, D. L. (1990). Priming and human memory systems. Science, 247, 301-305.

Tversky, A., \& Kahneman, D. (1973). Availability: A heuristic for judging frequency and probability. Cognitive Psychology. 5, 207232.

Tversky, A., \& Kahneman, D. (1974). Judgment under uncertainty: Heuristics and biases. Science, 185, 1124-1131.

Underwood, B. J. (1965). False recognition produced by implicit verbal responses. Journal of Experimental Psychology, 70, 122129.

Warrington, E. K., \& Weiskrantz, L. (1974). The effect of prior learning on subsequent retention in amnesic patients. Neuropsychologia, 12, 419-428.

Weiskrantz, L., \& Warrington, E. K. (1975). The problems of the amnesic syndrome in man and animals. In R. L. Isaacson \& K. H. Pribram (Eds.), The hippocampus (Vol. 2, pp. 411-428). New York: Plenum Press.

Whittlesea, B. W. A., Jacoby, L. L., \& Girard, K. (1990). Illusions of immediate memory: Evidence of an attributional basis for feelings of familiarity and perceptual quality. Journal of Memory and Language, 29, 716-732.

Wilkins, M. C. (1928). The effect of changed material on ability to do formal syllogistic reasoning. Archives of Psychology, 16, 102.

Woodworth, R. S., \& Sells, S. B. (1935). An atmosphere effect in formal syllogistic reasoning. Journal of Experimental Psychology, I8, 451-460.

Yates, J. F. (1990). Judgment and decision making. Englewood Cliffs, NJ: Prentice-Hall.

Received October 30, 1991

Revision received February 4, 1992

Accepted May 13, 1992

\section{APA Convention "Call for Programs"}

The "Call for Programs" for the 1993 APA annual convention appears in the October issue of the APA Monitor. The 1993 convention will be held in Toronto, Ontario, Canada, from August 20 through August 24. Deadline for submission of program and presentation proposals is December 10,1992. Additional copies of the "Call" are available from the APA Convention Office, effective in October. As a reminder, agreement to participate in the APA convention is now presumed to convey permission for the presentation to be audiotaped if selected for taping. Any speaker or participant who does not wish his or her presentation to be audiotaped must notify the person submitting the program either at the time the invitation is extended or prior to the December 10 deadline for proposal submission. 